\title{
Comparação da sensibilidade de técnicas diagnósticas diretas para identificação de babesiose em equinos
}

\author{
Comparison of direct diagnostic techniques for the identification of babesiosis in horses \\ Fabiola Souza de Carvalho', Gustavo Mendes Gomes', Paulo de Tarso Langraf Botteon², Ana Paula

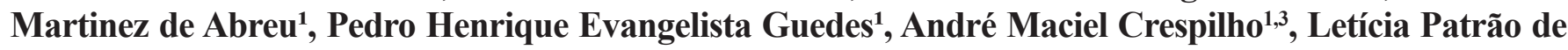 \\ Macedo Gomes'.
}

Como citar esse artigo. Carvalho FS, Gomes GM, Botteon PTL, Abreu APM, GuedesPHE, CrespilhoAM,GomesLPM. Comparação da sensibilidade de técnicas diagnósticas diretas para identificação de babesiose em equinos. Revista Saúde. 2014 Jan./Dez.; 05 (1/2): 05-10.

\begin{abstract}
Babesiosis has been described as one of the main diseases demanding a rapid and efficient diagnosis because of the considerable economic loss it might bring in Brazilian equine culture. The present study aims to compare the sensitivity of three direct diagnostic techniques for equine babesiosis: investigation of blood-borne parasites in total blood count smear, in peripheral blood smear and in splenic punction blood smear.Thirteen equines between 7 and 20 years old, weighing inaverage $341 \mathrm{~kg}$ were part of the study. The blood samples were collected between January and March of 2014. The splenic punction blood smear was more sensitive to identify positive animals in comparison to the other two techniques. Keywords: Diagnosis. Babesiosis. Equine. Spleen. Splenicpunction.
\end{abstract}

\begin{abstract}
Resumo
A babesiose tem sido descrita como uma das principais enfermidades na equideocultura brasileira, gerando consideráveis perdas econômicas, o que exige diagnóstico rápido e eficaz. $\mathrm{O}$ objetivo deste estudo foi comparar a sensibilidade de três técnicas diagnósticas diretas na detecção dessa doença, sendo elas:a submetidos ao estudo 13 equinos com faixa etária entre 07 e 20 anos e peso médio de $341 \mathrm{~kg}$. As coletas foram realizadas entre os meses de janeiro e março de 2014. Das técnicas avaliadas, o esfregaço sanguíneo de punção esplênica apresentou maior sensibilidade na identificação de animais positivos quando comparado às demais. Palavras-chave: Diagnóstico. Babesiose. Equino. Baço. Punção esplênica.
\end{abstract}

\section{Introdução}

A equideocultura no Brasil tem se mostrado uma atividade de grande importância para a economia nacional, atingindo um faturamento anual de $\mathrm{R} \$ 7,5$ bilhões, gerando cerca de 3,2 milhões de empregos diretos e indiretos ${ }^{1}$. Neste cenário, a babesiose, descrita como a única doença intraeritrocitária dos equinos, tem sido apontada como uma das principais enfermidades que atingem o Complexo Agronegócio Cavalo devido à geração de danos como diminuição do rendimento, tanto atlético como reprodutivo, mortalidade, gastos com tratamentos e principalmente impedimento do trânsito internacional de animais soropositivos ${ }^{(2,3,4)}$.

Também denominada como piroplasmose e nutaliose $^{5}$, esta afecção acomete não só equinos, mas também asininos, muares, zebras e seus híbridos e tem por agentes etiológicos os protozoários Babesiacaballi e Theileriaequi ${ }^{(6,7)}$. Epidemiologicamente, a babesiose é classificada como endêmica em zonas tropicais e subtropicais em razão das condições climáticas destas áreas propiciarema existência de diversas espécies de carrapatos vetores, os quais transmitem os protozoários responsáveis pela doença ao hospedeiro vertebrado durante seu repasto sanguíneo ${ }^{8}$. No Brasil as espécies Dermacentornitens, Riphicephalus (Boophilus) microplus e Amblyoma cajennense têm sido associadas à transmissão da Babesiose ${ }^{(5,8)}$.

A doença caracteriza-se por apresentar uma fase aguda com picos febris maiores ou iguais à $40^{\circ} \mathrm{C}$, anorexia, anemia hemolítica, petéquias em mucosas, icterícia, edema em regiões baixas do corpo e distúrbios gastrointestinais como cólicas e fezes com secreção mucóide, bem como uma fase crônica, em que o animal torna-se portador assintomático ${ }^{(9,10,11)}$.

Pelos prejuízos econômicos diretos e indiretos e a capacidade de animais portadores serem fontes de infecção, faz-se exigência de diagnósticos rápidos e eficazes ${ }^{12}$. O diagnóstico desta afecção pode ser feito de forma direta,através da visualização do protozoário

1. Universidade Severino Sombra, USS, Vassouras-RJ, Brasil.

2. Universidade Federal Rural do Rio de Janeiro, UFRRJ, Seropédica-RJ, Brasil.

3. Universidade Santo Amaro, UNISA, São Paulo-SP, Brasil. 
em esfregaço sanguíneo, através da replicação do DNA do antígeno, ou ainda de forma indireta,por sorologia, sendo sempre levados em consideração: a clínica, os resultados laboratoriais e o histórico do animal ${ }^{(5,12)}$.

Os eritrócitos parasitados na corrente sanguínea incorporam o antígeno em suas membranas, induzindo à opsonização pelos anticorpos e acarretando sua remoção pelo sistema mononuclear fagocitário. $\mathrm{O}$ baço, por ser um órgão considerado como o maior sítio de resposta imune para antígenos provenientes da circulação sanguínea, apresenta maior concentração de hemácias parasitadas, tendo importante função na hemocaterese $\mathrm{e}^{7}$. Desta forma, estudos recentes têm destacado o esfregaço sanguíneo proveniente da punção esplênica como uma boa alternativa para se alcançar um diagnóstico rápido, com maior sensibilidade quando comparado ao esfregaço de sangue da jugular (sangue total) e de esfregaço de sangue da ponta de orelha (sangue periférico), e de custo mais acessível quando comparado aos métodos sorológicos ${ }^{(3,4)}$.

O objetivo do presente estudo foi comparar a sensibilidade de três técnicas diagnósticas diretas para babesiose: esfregaço de sangue total obtido por punção da veia jugular, esfregaço de sangue periférico obtido da ponta de orelha e esfregaço de punção esplênica

\section{Material e Métodos}

A metodologia deste estudo foi analisada e aprovada pela Comissão de Ética no Uso de Animais (CEUA) da Universidade Severino Sombra sob o protocolo 037/2013.

Foram submetidos ao estudo13 equinos, sendo 11 fêmeasda raça Mangalarga Marchador e dois machos sem raça definida (SRD). Os animais tinham entre $07 \mathrm{e}$ 20 anos, peso médio de $341 \mathrm{~kg}$ e eram criados parte em regime extensivo e parte em semi extensivo.

Para a verificação da idade, foi utilizada a avaliação da arcada dentária e para a avaliação do escore corporal,utilizou-se escala com pontuação de 0 a 10 , conforme métodos descritos porMcManus ${ }^{13}$.

As coletas foram realizadas entre os meses de janeiro e março de 2014. Para a contenção dos animais utilizaram-se cabrestos, tronco de contenção e contenção derivativa ("cachimbo"), não sendo necessária a utilização de sedativos ou anestésicos.

Para a coleta em ponta de orelha,foi realizada primeiramente a antissepsia do local com algodão embebido em álcool $70 \%$, seguida pela punção de veia periférica da extremidade da orelha com agulha $25 \times 7$ (Figura 1). A primeira gota obtida foi captada com pipetadora automática, sendo o sangue transferido para lâmina de vidro para a posterior confecção do esfregaço.

Para coleta em veia jugular, realizou-se a antissepsia do local com algodão embebido em álcool $70 \%$. Com uma das mãos, fez-se o garrote pressionando a jugular. Em seguida, fez-se punção da veia para coleta de um volume total de $4 \mathrm{~mL}$ (figura 2). A amostra de sangue obtida foi transferida para um tubo com EDTA, que foi acondicionado em isopor com gelo, para posterior confecção de esfregaço em lâmina.

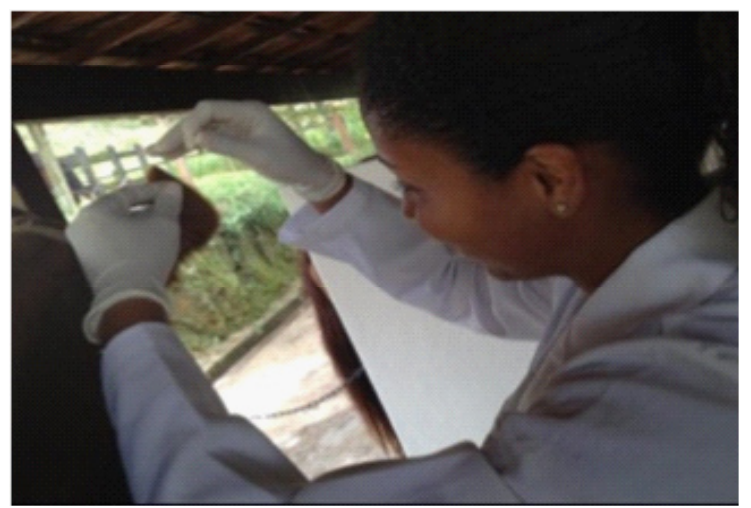

Figura 1. Punção de Veia Periférica da Ponta da Orelha Fonte: Arquivo Pessoal, 2014.

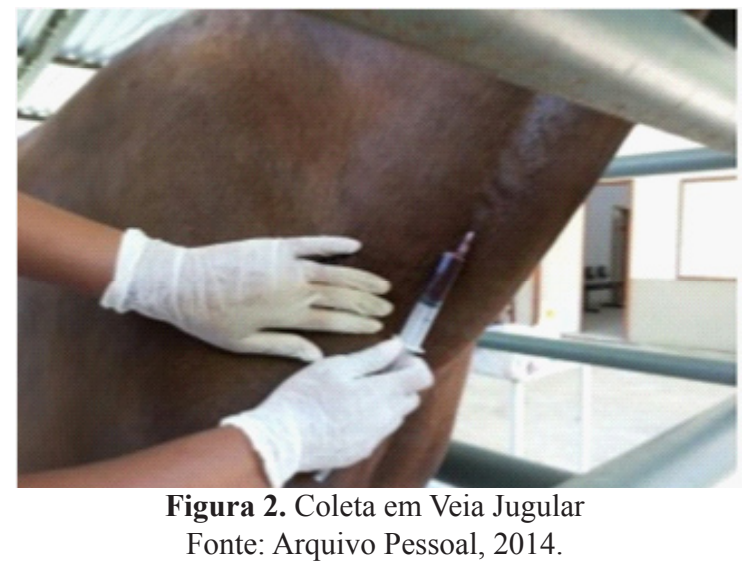

Para a punção esplênica, a técnica utilizada foi a descrita por Souza e colaboradores ${ }^{5}$. Inicialmente fez-se a contagem dos espaços intercostais para a certificação do local da punção, sendo este localizado na borda cranial do décimo sétimo espaço intercostal, antímero esquerdo do animal. Para a determinação da localização no eixo dorso ventral, foi seguida a descrição da anatomia topográfica do baço de Popesko ${ }^{14}$ e de Ashdown ${ }^{15}$.

A região do acesso foi lavada com água e sabão neutro e realizou-se a tricotomia numa área de $3 \mathrm{~cm}^{2}$. A antissepsia no local da punção foi feita com gaze embebida em PVPI degermante, sendo finalizada com gaze eclorexidine 5\%. Fez-se a punção com agulha 30x8 em um ângulo de $90^{\circ}$ com a pele. Com seringa de $3 \mathrm{ml}$ contendo heparina, coletou-se, por aspiração, um volume entre 0,4 e $1 \mathrm{~mL}$ de sangue para a confecção do esfregaço (Figura 3 ).

Foi implementada a única recomendação encontrada na literatura quanto à técnica, que é a de se evitar exercícios físicos extenuantes dos animais dois 
dias antes e dois dias depois da punção, sendo liberadas caminhadas leves ${ }^{16}$.

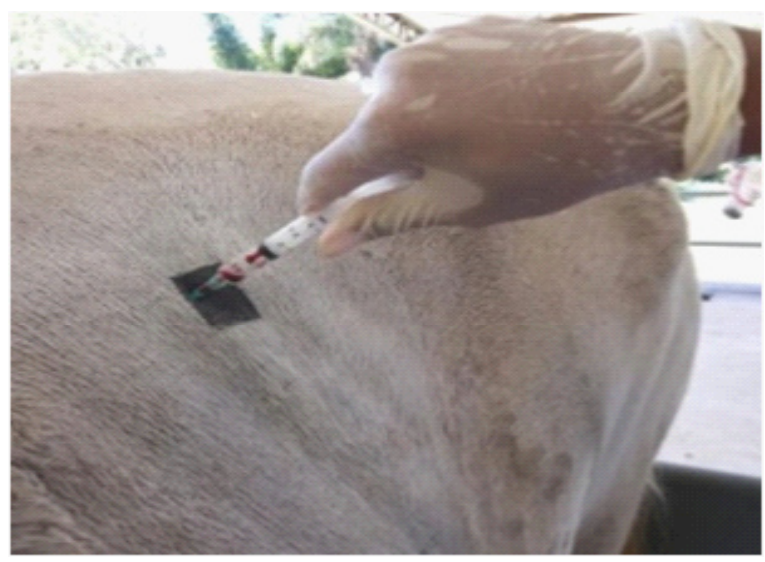

Figura 3. Coleta de sangue esplênico por aspiração. Fonte: Arquivo Pessoal, 2014.

Os esfregaços foram confeccionados logo após as coletas e,depois da secagem em temperatura ambiente, a coloração das lâminas em Panótico Rápido foi realizada com imersão de 20 segundos em cada corante e lavagem em água corrente. Para cada técnica avaliada (punção de sangue em jugular, punção em ponta de orelha e punção esplênica) foram confeccionadas 3 lâminas de cada animal.

As lâminas foram analisadas em microscopia óptica, com óleo de imersão e objetiva de 100x, para pesquisa dos hemoparasitas causadores da babesiose, a saber, T. equi e B. caballi. Para visualização dos hemoparasitas, as lâminas foram rastreadas pelas bordas laterais ( 10 campos cada borda) e pela franja (10 campos) dos esfregaços sanguíneos.

Todas as amostras foram analisadas pela docente responsável pelo Laboratório Clínico Veterinário da Universidade Severino Sombra, Vassouras- RJ. Os dados obtidos na identificação dos hemoparasitas foram tabulados para a análise estatística das técnicas diagnósticas, agrupadas duas a duas. Foram realizadas a análise do coeficiente kappa, que demonstra o coeficiente de concordância entre duas técnicas diagnósticas; percentagem de concordância, que representa a percentagem de resultados idênticos obtidos entre as técnicas; valor de p para avaliar o nível de significância estatística das análises; e replicabilidade, a qual expressa a possibilidade de se reproduzir o experimento em questão.

\section{Resultados}

Dos 13 animais avaliados, todos foram diagnosticados positivos para babesiose, uma vez que o agente etiológico foi identificado em pelo menos uma das técnicas avaliadas.

Durante o exame clínico efetuado no dia das coletas sanguíneas, observou-se escore corporal variando entre 3 e 7 pontos; peso médio de $341 \mathrm{Kg}$; e idade variando entre 07 e 20 anos (Tabela 1).

Tabela 1. Estimativa de idade, escore corporal e peso dos 13 animais avaliados.

\begin{tabular}{|c|c|c|c|}
\hline ANIMAIS & $\begin{array}{c}\text { IDADE } \\
\text { (anos) }\end{array}$ & $\begin{array}{c}\text { ESCORE } \\
(\mathbf{0 - 1 0})\end{array}$ & $\begin{array}{c}\text { PESO } \\
\text { (Kg) }\end{array}$ \\
\hline 01 & 10 & 3 & 340 \\
\hline 02 & 9 & 3 & 350 \\
\hline 03 & 7 & 4 & 380 \\
\hline 04 & 9 & 4 & 350 \\
\hline 05 & 20 & 3 & 347 \\
\hline 06 & 18 & 3 & 400 \\
\hline 07 & 10 & 4 & 450 \\
\hline 08 & 14 & 7 & 436 \\
\hline 09 & 10 & 7 & 365 \\
\hline 10 & 9 & 7 & 340 \\
\hline 11 & 14 & 7 & 413 \\
\hline 12 & 12 & 7 & 325 \\
\hline 13 & 18 & 5 & 286 \\
\hline $\begin{array}{l}\text { Parâmetros } \\
\text { Normais }\end{array}$ & - & - & - \\
\hline
\end{tabular}

Quanto ao percentual de identificação dos hemoparasitas, as técnicas de punção esplênica, ponta de orelha e jugular apresentaram, respectivamente: $92 \%$ $(12 / 13), 77 \%(10 / 13)$ e $31 \%(4 / 13)$. Quanto ao percentual de sensibilidade, as mesmas técnicas apresentaram, respectivamente: $92,86 \%, 81,25 \%$ e $59,09 \%$, conforme dados descritos na Figura 4.

Quanto ao agente etiológico, em 100\% (13/13) dos animais o protozoário $T$. equi foi identificado e em $8 \%(1 / 13)$ T. equi e B.caballi foram identificados concomitantemente, conforme descrito na Tabela 2.

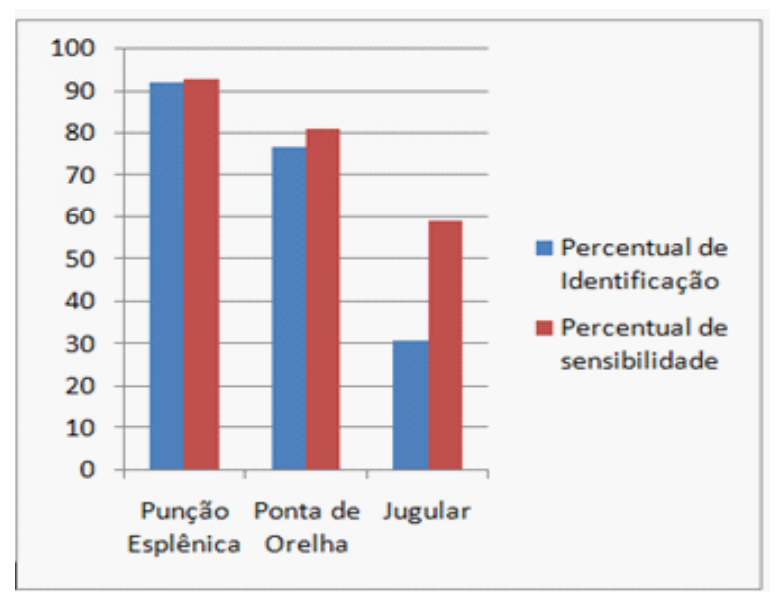

Figura 4. Percentual de identificação dos hemoparasitas e de sensibilidade das técnicas. 
Tabela 2. Resultados da pesquisa de T. equi e B. caballi em esfregaços sanguíneos de punção esplênica, jugular e ponta de orelha.

\begin{tabular}{c|c|c|c|c|c|c}
\multirow{2}{*}{ Animais } & \multicolumn{2}{|c|}{ Punção Esplênica } & \multicolumn{2}{c|}{ Ponta de Orelha } & \multicolumn{2}{c}{ Jugular } \\
& T. equi & B. Caballi & T. equi & B. Caballi & T. equi & B. Caballi \\
\hline 01 & - & - & + & - & - & - \\
\hline 02 & + & - & - & - & - & - \\
\hline 03 & + & - & + & - & - & - \\
\hline 04 & + & - & + & - & + & - \\
\hline 05 & + & - & + & - & - & - \\
\hline 06 & + & - & - & - & + & + \\
\hline 07 & + & - & - & - & - & - \\
\hline 08 & + & - & + & - & - & - \\
\hline 09 & + & - & + & - & - & - \\
\hline 10 & + & - & + & - & + & - \\
\hline 11 & + & - & + & - & - & - \\
\hline 12 & + & - & + & - & + & - \\
\hline 13 & + & - & + & - & - & - \\
\hline
\end{tabular}

Nota: (+) positivo; (-) negativo

Em nenhuma amostra positiva para $T$. equi foi identificada a forma "Cruz de Malta", sendo visualizado um único trofozoíto ou dois trofozoítos dentro do eritrócito. Na amostra positiva para $B$. caballi foram visualizados dois trofozoítosintraeritrocitáriosunidos em uma de suas extremidades, formando um ângulo agudo.

Considerando que todos os animais foram diagnosticados positivos em pelo menos um dos métodos diagnósticos, os resultados negativos foram interpretados como falso-negativos. A técnica de esfregaço sanguíneo de jugular foi a que apresentou o maior número de resultados deste tipo: $69 \%(9 / 13)$ das amostras. Seguida da técnica de ponta de orelha com $23 \%$ (3/13) e punção esplênica com $8 \%$ (1/13), ou seja, com menor valor de resultados falso-negativos.

Quanto aos valores do coeficiente kappa, foram verificados valores negativos na análise de jugular versus esplênica $(-0,6154)$ e na análise de ponta de orelha versus esplênica $(-0,1538)$, e valor ligeiramente positivo na análise de ponta de orelha versus jugular $(0,0769)$. Isto é, nas duas primeiras análises houve baixa concordância entre as técnicas diagnósticas confrontadas, enquanto na terceira análise verificou-se pequena concordância (Tabela 3 ).

$\mathrm{Na}$ análise de percentagem de concordância encontrou-se maior valor em ponta de orelha versus jugular $(54 \%)$, seguido de ponta de orelha versus esplênica (42\%) e jugular versus esplênica (19\%). Quanto ao valor de $p$, não houve significância estatística nas análises entre ponta de orelha versus jugular $(\mathrm{p}=$ $0,3292)$ e ponta de orelha versus esplênica $(\mathrm{p}=0,1385)$, porém houve significância estatística $(\mathrm{p} \leq 0,05)$ na análise entre jugular versus esplênica $(\mathrm{p}=0,0006)$. Em todas as análises foi verificada fraca replicabilidade, isto é, ao se repetirem as mesmas técnicas diagnósticas com outras amostras podem ser encontrados valores diferentes aos deste experimento (Tabela 3 ).

Tabela 3. Valores do coeficiente kappa, percentagem de concordância, valor de p e replicabilidade das técnicas diagnósticas testadas.

\begin{tabular}{|c|c|c|c|}
\hline & \multicolumn{3}{c|}{ TÉCNICAS DIAGNÓSTICAS } \\
\cline { 2 - 4 } & Jugular X Esplênica & Ponta de Orelha X Esplênica & Ponta de Orelha X Jugular \\
\hline Kappa & $-0,6154$ & $-0,1538$ & 0,0769 \\
\hline Concordância (\%) & $19 \%$ & $42 \%$ & $54 \%$ \\
\hline Valor de $\mathrm{p}$ & $0,0006^{*}$ & 0,1385 & 0,3292 \\
\hline Replicabilidade & Fraca & Fraca & Fraca \\
\hline
\end{tabular}

Nota: valor de $p \leq 0,05^{*}$ 


\section{Discussão}

Não foi analisada a susceptibilidade dos animais à babesiose quanto ao gênero, faixa etária ou raça, visto que não foi objetivo inicial deste experimento.

Para a captação da amostra em ponta de orelha foi utilizada apipetadora automática. Este procedimento foi instituído por dois motivos: para diminuir a sujidade no esfregaço sanguíneo, muito comum em amostras coletadas diretamente na lâmina, fato descrito por Meirelles ${ }^{17}$ como prejudicial para a leitura das mesmas; e para a obtenção da primeira gota de sangue que, conforme Spiewak ${ }^{18}$, é mais eficaz na detecção de Babesiasp, pelo fato das hemácias parasitadas serem maiores e sofrerem estase na circulação capilar.

Para a coleta de sangue por punção esplênica foi seguida a técnica descrita por Souza e seus colaboradores ${ }^{4}$, porém, em sua execução a heparina foi substituída pelo EDTA. Alguns pesquisadores relatam que a heparina pode causar alterações na morfologia de leucócitos e problemas na agregação plaquetária. Entretanto, durante a análise, não foi observada nenhuma interferência desse anticoagulante na avaliação dos eritrócitos, sendo considerado satisfatório o seu uso neste experimento.

Não foi encontrada na literatura consultada, referência quanto à localização precisa do baço em relação ao eixo dorso-ventral, sendo descrita por Souza $^{4}$ somente sua localização em relação ao eixo crânio- caudal. Desta forma, para aplicação da técnica de punção esplênica,foi utilizada a descrição de Popesko $^{14}$ e Ashdown ${ }^{15}$ da anatomia topográfica dos órgãos abdominais à altura da décima sétima vértebra torácica.

Observou-se, durante a punção do baço, maior facilidade na obtenção da amostra em animais com escore corporal mais elevado. Souza e colaboradores ${ }^{19}$ descrevem que animais com maior escore corporal podem apresentar aumento efetivo em seu depósito de gordura visceral, o que promove maior compressão das vísceras contra a parede abdominal, facilitando assim a coleta.

Dos 13 animais avaliados, $100 \% \quad(13 / 13)$ obtiveram diagnóstico positivo em pelo menos uma das técnicas sem que houvesse manifestação clínica da doença.A prevalência foi de $100 \%(13 / 13)$ para T. equi e $8 \%$ (1/13) para T. equi e B.caball iconcomitantemente. Este resultado está de acordo com o experimento de Meirelles ${ }^{17}$ que encontrou alta ocorrência ao avaliar 27 éguas no Centro Avançado de Reprodução Equina no município de Vassouras-RJ. Em seu estudo, 74\% (20/27) dos animais foram diagnosticados positivos para babesiose, sendo $95 \%(19 / 20)$ para $T$. equi e 5\% para B. caballi.

A babesiose é consideradaenzoótica em algumas áreas da América do Sul, dentre elas o Brasil. De acordo com Roncati ${ }^{8}$ e Bezerra ${ }^{12}$ os dois protozoários estão presentes no território brasileiro, podendo ocorrer infecções mistas. Entretanto, os mesmos autores relatam uma maior prevalência da infecção por $T$. equi, fato também observado nesta pesquisa.

Quanto à taxa de identificação dos agentes etiológicos e ao percentual de sensibilidade das técnicas avaliadas, os maiores valores foram encontrados no esfregaço sanguíneo de punção esplênica, seguido do esfregaço de ponta de orelha e esfregaço de jugular. Estes valores estão de acordo com os encontrados por Meirelles ${ }^{17}$ que, ao comparar o esfregaço sanguíneo de jugular com o de ponta de orelha para diagnóstico da babesiose, encontrou $50 \%$ de resultados positivos no primeiro e $85 \%$ no segundo. Os resultados também foram semelhantes aos de Souza ${ }^{4}$ que confrontaram as técnicas utilizando esfregaço de sangue periférico e de punção esplênicae encontraram maior taxa de identificação e sensibilidade utilizando o sangue do baço.

A maior percentagem de identificação e de sensibilidade do esfregaço de sangue esplênico pode ser explicada em razão de o baço ser um órgão com importante função na hemocaterese. Logo,possui uma maior concentração de hemácias parasitadas. Segundo $\mathrm{Fonseca}^{7}$, na fase crônica da doença o sangue periférico apresenta somente $0,01 \%$ de células parasitadas e isto diminui consideravelmente as chances de visualização do hemoparasita.

Na comparação entre as técnicas utilizando sangue total (jugular) e sangue periférico (ponta de orelha), a última apresentou maior número de identificações $\mathrm{e}$ maior percentual de sensibilidade. Como justificativa, destaca-se o menor calibre dos vasos sanguíneos da circulação periférica. De acordo com Garcia ${ }^{6}$, a circulação capilar apresenta maior número de eritrócitos parasitados e o sangue proveniente dela é mais indicado para o diagnóstico de doenças intraeritrocitárias.

Resultados falso-negativos também foram relatados por Souza $^{4}$ que comparou esfregaços de punção esplênica com o teste ELISA e encontrou 42\% de resultados falso-negativos na primeira técnica. Fonseca ${ }^{7}$ avaliou 15 equinos e $40 \%$ (6/15) foram diagnosticados positivos para babesiose no esfregaço sanguíneo de punção esplênica, porém nenhum resultado positivo foi encontrado na análise dos esfregaços de ponta de orelha. Meirelles ${ }^{16}$ obteve $50 \%(10 / 20)$ de resultados falso-negativos no esfregaço de sangue total quando comparado ao esfregaço de sangue periférico.

Os resultados falso-negativos obtidos nos esfregaços sanguíneos de punção esplênica podem ser fundamentados nas afirmações de Fonseca ${ }^{7}$.Para o autor, nenhum dos testes diagnósticos existentes para babesiose apresenta todos os requisitos de sensibilidade, especificidade, reprodutibilidade, simplicidade, custo benefício e rapidez. 
Piotto $^{5}$ afirma que animais na fase crônica da doença apresentam baixa parasitemia $(0,01 \%)$, o que diminui as chances de diagnóstico positivo.

\section{Conclusão}

Concluiu-se que na comparação entre as técnicas diagnósticas avaliadas, o esfregaço sanguíneo por punção esplênica obteve maior percentual de sensibilidade e maior número de identificação de amostras positivas para babesiose. Entretanto, apesar de ter identificado um número satisfatório de amostras positivas, não é possível afirmar que este seja melhor método de diagnóstico da doença. Para isso, são necessários mais estudos e um número maior de animais testados para o aperfeiçoamento das técnicas.

\section{Referências}

${ }^{1}$ Almeida FQ, Silva VP. Progresso científico em equideocultura na $1^{\mathrm{a}}$ década do século XXI. Revista Brasileira de Zootecnia, v.39, p.119-129, 2010.

${ }^{2}$ Morris DD. Doenças do Sistema Hemolinfático. In: Medicina Interna Equina. 1. ed. Rio de Janeiro: Guanabara Koogan, 2000 p. 491.

${ }^{3}$ Nizoli LQ. Alterações hematológicas e humorais de equinos expostos à infecção por Babesiaequi, na região sul do Rio Grande do Sul. Pelotas (SP): Faculdade de Veterinária. Universidade Federal de Pelotas, 2005.

${ }^{4}$ Souza MVM, Moreira MAB, Corrêa RR, Roncati NV. [2007]. Diagnóstico de Babesiose equina por punção esplênica. In: ABRAVEQ, 2007. Disponível em: <http://www.abraveq.com.br/novo_2007/artigo_0009.html> Acesso em: $23 / 08 / 13$

${ }^{5}$ Piotto MA. Determinação da infecção por Theileriaequi e Babesiacaballi em equinos alojados no Jóquei Clube de São Paulo por meio de técnica de C-ELISA. São Paulo: Faculdade de Medicina Veterinária e Zootecnia. Departamento de Clínica Médica. Universidade de São Paulo, 2009.

${ }^{6}$ Garcia LPF. Alterações Hematológicas Encontradas em Equinos com TheileriaEqui (T. equi)e Babesiacaballi (B. caballi). Sorocaba (SP): Centro de Ciências Agrárias. Curso de Especialização em Patologia Clínica Veterinária. Universidade Castelo Branco, 2008.

${ }^{7}$ Fonseca LA. Reação em cadeia de polimerase (PCR) de sangue periférico e esplênico para diagnóstico de babesia equina. Brasília: Faculdade de Agronomia e Medicina Veterinária. Universidade de Brasília, 2012.

${ }^{8}$ Roncati NV. Ocorrência de Theileriaequi congênita em potros Puro Sangue Lusitano no Brasil, diagnosticada através da técnica de RT-PCR. São Paulo: Faculdade de Medicina Veterinária e Zootecnia da Universidade de São Paulo, 2006.

${ }^{9}$ Nogueira CEW, Silva SS, Nizoli LQ, Ribas LM, Albuquerque LPAN. Efeito quimioprofilático do dipropionatoimidocarb na prevenção da agudização de Babesiose equina em cavalos portadores da infecção. A Hora Veterinária, n. 146, p.14-17, 2005.

${ }^{10}$ Thomassian A. Enfermidade dos cavalos. 4. Ed. São Paulo: Varela, 2005.

${ }^{11}$ Golynski AA. Aspectos epidemiológicos da Babesiose equina na região norte do Estado do Rio Grande do Sul. Rio de Janeiro: Instituto de Veterinária. UFRRJ, 2007.

${ }^{12}$ Bezerra LL. Eficiência Reprodutiva De Éguas Assintomáticas Portadoras De TheileriaEqui Submetidas A Um Programa de Transferência de Embrião. Rio de Janeiro: UFRRJ, 2011.

${ }^{13}$ Macmanus C, Louvandini H, Dallago B, Melo CB, Seixas L. Estimando a idade de um animal usando os dentes. 2010. 27p. Disponível em $<$ www. animal.unb.br>. Acesso em 28/03/2014 (Informação Genéticosanitária da Pecuária Brasileira - INCT Série Técnica Genética).
${ }^{14}$ Popesko P. Atlas de anatomia topográfica dos animais domésticos, São Paulo: Manole, 1997. 3 v.

${ }^{15}$ Ashdown RR, Done SH. 2. ed. Atlas Colorido de Anatomia Veterinária de Equinos, São Paulo: Elsevier, 2011. 349 p.

${ }^{16}$ Kono S, Yamagiwa S, Haga T, Hamada S, Hirato K, Honma K, Ishikawa T, Miura S, Ohya M, Sakai T, Takahata K, Yamashita J, Ohga A. Morphological studies on the spleen punctate in equine infectious anemia. From the nationalinstitute of animal health, Ministry of agriculture and forestry.Tokyo, Japan: KOKKAIDO University, 1952.

17 Meirelles AB. Frequência da perda embrionária precoce em éguas receptoras portadoras de Theileriaequi. Vassouras (RJ): Universidade Severino Sombra, 2011.

18 Spiewak G. Aspectos Epidemiológicos, clínicos e de diagnósticos da infecção por Babesia canis, em cães atendidos em clínicas veterinárias em Belo Horizonte. Belo Horizonte (MG): Universidade Federal de Minas Gerais, 1992.

19 Souza AL, Arruda IJ, Rondina R. Função, controle transcricional e atividade endócrina do tecido adiposo dos mamíferos. ACSA - Agropecuária Científica no Semi-Árido, v. 05, p. 01- 15, 2009. 